\title{
CPT Model-Based Prediction of the Temporal and Spatial Distributions of Passenger Flow for Urban Rail Transit under Emergency Conditions
}

\author{
Wei Li $\mathbb{D}^{\text {, }}$, Min Zhou $\mathbb{D}^{\mathbb{D}}$, and Hairong Dong \\ State Key Laboratory of Rail Traffic Control and Safety, Beijing Jiaotong University, Beijing, China \\ Correspondence should be addressed to Min Zhou; zhoumin@bjtu.edu.cn
}

Received 4 September 2020; Revised 10 November 2020; Accepted 4 December 2020; Published 15 December 2020

Academic Editor: Wen LIU

Copyright ( 2020 Wei Li et al. This is an open access article distributed under the Creative Commons Attribution License, which permits unrestricted use, distribution, and reproduction in any medium, provided the original work is properly cited.

\begin{abstract}
Emergencies have a significant impact on the passenger flow of urban rail transit. It is of great practical significance to accurately predict the urban rail transit passenger flow and carry out research on its temporal and spatial distributions under emergency conditions. Urban rail transit operating units currently use video surveillance information mainly to process emergencies and rarely use computer vision technology to analyze passenger flow information collected. Accordingly, this paper proposes a passenger flow-based temporal and spatial distribution model for urban rail transit emergencies based on the CPT. First, this paper clarifies the categories and classification of urban rail transit emergencies, analyzes the factors affecting passenger route selection, and establishes a generalized travel cost model for passengers under emergencies. Second, this paper establishes a passenger route choice behavior model for urban rail transit based on the cumulative prospect theory. Finally, taking Beijing as an example, this paper analyzes passenger travel behavior under emergencies based on multiple logistic regression models and analyzes the impact of emergencies on rail transit travel behavior. The research results show that the cumulative prospect theory can better describe the route choice behavior of rail transit passengers under emergencies than the existing models, and this model is of great significance for handling urban rail transit emergencies. The model proposed in this paper can provide a theoretical basis for the government and relevant departments to formulate traffic management measures.
\end{abstract}

\section{Introduction}

Urban rail transit, which is intensifying, is characterized by fast speed, large capacity, high efficiency, and low energy consumption and has become the main form of urban public transportation. With the development of urban rail transit networks, urban rail transit has become the first choice for commuter passengers, with concentrated passenger flows during the morning and evening travel peaks. The stability and reliability of rail transit operation are of great significance to the stable development of urban transportation. However, with an increasing number of lines, the strictness of equipment standards, the aging of equipment and other reasons, and the types of emergencies that occur are gradually diversifying, their frequency of occurrence is increasing, and the spatial scope is expanding [1]. Once an emergency occurs, the normal operation of the train will be affected. If emergencies are not dealt with in a timely manner, the transportation capacity of urban rail transit will be reduced, and traffic paralysis may occur. In the case of urban rail transit network operation, research is carried out on the real-time prediction and early warning of the temporal and spatial distributions of passenger flow in the case of rail transit emergencies to accurately grasp the temporal and spatial distributions of passenger flow in the rail transit network. The impact of the incident, the improvement of real-time passenger flow monitoring capabilities and passenger travel information service levels, the effective organization of subway passenger flow, and the strengthening of subway passenger flow control are all of great significance.

To predict the temporal and spatial distributions of urban rail transit under normal operating conditions and to 
provide an early warning of large passenger flows, many studies have been carried out both at home and abroad [2-5]. At present, forecasting the temporal and spatial distributions of passenger flow is mainly aimed at highdensity areas such as major event venues and transportation hubs. When investigating the route choice behavior of urban rail transit passengers under normal operating conditions, researchers generally combine historical data and traditional model methods. However, it is difficult to predict the selection behavior of urban rail transit passengers under emergency conditions, and it is difficult to conduct in-depth research with traditional models and methods. Research on rail transit passenger flow under emergencies mostly focuses on the prediction, propagation, evacuation, etc., of emergent passenger flow [6-13]. Current research mostly analyzes the impact of sudden passenger flow on urban rail operation from the perspective of train operation and passenger transportation organization, whereas relatively few studies have been conducted on the prediction and early warning of the temporal and spatial distributions of passenger flow in rail transit emergencies.

Preston et al. [14] analyzed the impact of train delays on passenger travel. Barron et al. [15] and Pnevmatikou et al. [16] considered the characteristics of passenger travel choice behavior under emergency situations. Tsuchiya et al. [17] developed a passenger support system to inform passengers of the best route to their destination in the event of an emergency. Sun et al. [18] established a model to evaluate the impacts of urban rail transit interruptions on travel times and delays based on a Bayesian method. Hong et al. [19] established a model to evaluate local interruptions in urban rail transit networks. Li and Liang [20] analyzed the impact of operating interruptions and proposed a quantitative calculation method for the scale of affected passengers. Huang et al. [21] studied the route selection of urban rail transit passengers under conditions of bounded rationality. Wang and $\mathrm{Wu}[22]$ analyzed the impact of emergencies on rail transit travel behavior. Wang [23], Luo [24], Qiao [25], and $\mathrm{Wu}$ [26] studied methods to calculate the affected passenger flows of basically unaffected passengers, bypass passengers, and passengers who are unable to reach their destination. Yu [27] proposed a passenger flow assignment method under interruption based on the MNL model. Liu [28] established a mathematical model to estimate the affected passenger flow under the interruption of urban rail transit. Xu et al. [29] established a passenger travel path selection model under urban rail transit emergencies based on the normal distribution probability model. Wang et al. [30] built an emergency logistics path selection model based on CPT, and the results showed that the parameter setting of the model has an important impact on the path selection model. Wang et al. [31] established a cumulative prospect model and concluded that travelers' attitudes toward risk are different under different decision-making behaviors.

In this paper, on the basis of defining the scope of emergency research, with the help of AFC data, historical emergency information, and questionnaire survey data, this paper uses historical emergency passenger selection behavior information to carry out data mining. At the same time, considering the limited rationality of passengers, based on the path selection model of cumulative prospect theory, this paper studies the spatial and temporal distributions of urban rail transit passenger flow under emergencies, carries out passenger flow guidance information release and earlywarning research, and verifies the effectiveness of the technology combined with specific cases to provide a reference for passenger flow organization and evacuation.

\section{Establishment of a Generalized Travel Cost Model}

2.1. Definition and Classification of Emergencies. An urban rail transit emergency refers to an event that occurs suddenly within the operating scope of urban rail transit that may damage the personal property and health of passengers or employees and requires the urban rail transit operation unit to make responsible decisions to minimize losses.

Different types of urban rail transit emergencies have different impacts on train operation. Passengers will choose different routes according to their own conditions, thus forming different temporal and spatial distributions of passenger flow in the urban rail transit network. The scope of this study is defined as follows: peak hours in the morning and evening under the occurrence of natural disasters, equipment failure, passenger transport organization and management scenarios, and other sudden, temporary large passenger flow events. In this paper, the types of urban rail transit emergencies are divided into three categories, as shown in Table 1.

\subsection{Establishment of a Generalized Travel Cost Model}

2.2.1. Analysis of Factors Affecting the Passenger Route Choice. In the urban rail transit network, when passengers choose a route, they are not only affected by individual subjective factors, such as individual comfort sensitivity requirements and familiarity with rail transit networks, but also by objective factors such as travel time, cost, and distance. The final passenger's route choice is a result of a comprehensive consideration. When any one attribute changes, the path selection may change. The influencing factors of passenger route selection are shown in Table 2.

\subsubsection{Establishment of a Generalized Travel Cost Model.} The urban rail transit network path refers to the connecting path between any two stations in a transportation network. The generalized passenger travel path includes the inbound channel from the inbound gate to the platform, the starting station platform, the section, the transfer channel of the transfer station, the terminating station, the outbound channel to the outbound gate, and the paths between all connections. The generalized travel cost of passengers refers to the total cost of travel time and money for passengers using rail transit, reflecting the comprehensive cost of passengers choosing a certain route.

This paper establishes a generalized travel cost model based on different weights of influencing factors on 
TABLE 1: Types of urban rail transit emergencies.

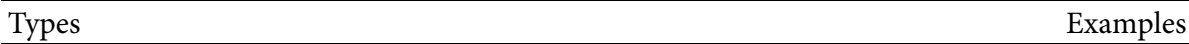

Natural disasters

Equipment failure

Passenger transport organization and management
Heavy rain, blizzard, strong wind, thunder and lightning, heavy fog, and low temperature Signal failure, power supply failure, line failure, and vehicle failure

People caught in the door, passengers falling off the platform, passenger conflicts, terrorist incidents, and transfer channels closed

TABLE 2: Influencing factors affecting the passenger route choice.

\begin{tabular}{|c|c|c|}
\hline Type & Name & Description \\
\hline \multirow[b]{2}{*}{$\begin{array}{l}\text { Subjective } \\
\text { factors }\end{array}$} & Comfort & Passengers will choose a more comfortable route to travel. \\
\hline & $\begin{array}{l}\text { Network } \\
\text { familiarity }\end{array}$ & $\begin{array}{l}\text { Passengers who are more familiar with the network will trust their own experience information more } \\
\text { and choose new routes to travel. Passengers who are not familiar with the network will only choose the } \\
\text { more familiar route to travel. }\end{array}$ \\
\hline \multirow{3}{*}{$\begin{array}{l}\text { Objective } \\
\text { factors }\end{array}$} & Time & Passengers will choose a route with a short travel time. \\
\hline & Cost & Passengers will choose a less expensive route to travel. \\
\hline & Distance & Passengers will choose a shorter route to travel. \\
\hline
\end{tabular}

passengers. The urban rail transit network route travel time is the main judgment parameter for route searching in the simulation model. To search for the path set between any two stations in the urban rail transit network, this paper establishes a generalized passenger travel cost model based on time. In an emergency, the model will dynamically update the interval of the period and the impedance on the node before each route search or passenger flow distribution.

$$
C_{k}^{O D}=\sum_{k}^{o} C_{\text {block }}^{d} * \gamma+\sum_{k}^{o} C_{\text {node }}+\sum_{k}^{o} C_{\text {transfer }}+{ }^{o} \vec{k}_{k}^{d} C_{\text {delay }}
$$

In formula (1), $C_{k}^{O D}$ is the comprehensive impedance cost function of the $k$-th path between the $O D$ pair; $C_{\text {block }}$ is the impedance cost of all sections of the path; $C_{\text {node }}$ is the node impedance cost of all intermediate stations; $C_{\text {transfer }}$ is the node impedance cost of all transfer stations; $\gamma$ is the congestion impedance function of the road section passing through; and $C_{\text {delay }}$ is the revised cost function under emergencies.

Each impedance fee can be expressed as follows:

(1) Section impedance cost $C_{\text {block }}$ :

$$
C_{\text {block }}=t_{\text {block }} * c_{\text {block }} \text {. }
$$

$$
\gamma=\left\{\begin{array}{l}
1 ; \quad \omega<\omega_{0} \\
1+\phi_{1}(\rho) *\left(\omega-\omega_{0}\right), \quad \omega_{0}<\omega<\omega_{1} ; \\
1+\phi_{1}(\rho) *\left(\omega_{1}-\omega_{0}\right)+\phi_{2}(\rho) *\left(\omega_{2}-\omega\right) ; \quad \omega_{1}<\omega<\omega_{2} \\
1+\phi_{1}(\rho) *\left(\omega_{1}-\omega_{0}\right)+\phi_{2}(\rho) *\left(\omega_{2}-\omega_{1}\right)+\phi_{3}(\rho) *\left(\omega-\omega_{2}\right) ; \quad \omega_{2}<\omega<\omega_{3}
\end{array}\right\} .
$$

In formula (2), $t_{\text {block }}$ is the travel time of the section, and $c_{\text {block }}$ is the travel cost per unit time, RMB/s.

(2) Node impedance cost of the intermediate station $C_{\text {node }}$ :

$$
C_{\text {node }}=t_{\text {node }} * c_{\text {node }} \text {. }
$$

In formula (3), $t_{\text {node }}$ is the stop time of the intermediate station, and $c_{\text {node }}$ is the stop cost per unit time, $\mathrm{RMB} / \mathrm{s}$.

(3) Node impedance cost of the transfer station $C_{\text {transfer: }}$ :

$C_{\text {transfer }}=\left(t_{\text {transfer }}+0.5 * E(h)\right) * f(\tau, p) * c_{\mathrm{ph}}$.

In formula (4), $t_{\text {transfer }}$ is the travel time of the transfer station; $E(h)$ is the expected time between rail transit arrivals; $f(\tau, p)$ is the magnification penalty function on the crowded people and the number of transfers; $\tau$ is the transfer penalty coefficient; $p$ is the number of transfers; and $c_{p h}$ is the transfer fee for passengers at transfer stations per unit time, $\mathrm{RMB} / \mathrm{s}$.

(4) Congestion impedance function $\gamma$ :
In formula (5), $\phi(\rho)$ is the congestion penalty amplification function, and $\omega$ is the critical perception 
(5) Amendment fees for emergencies $\sum_{k}^{o} \longrightarrow \mathrm{d} C_{\text {delay }}$ : According to statistics, the delay time of emergencies obeys a similar discrete probability distribution. The occurrence of emergencies will have certain impacts on the corresponding lines, stations, and sections, such as slower trains and delays caused by congested transfers, which will increase the travel time of passengers who choose that route.

\section{Prediction and Early Warning of the Temporal and Spatial Distributions of Passenger Flow}

3.1. Passenger Route Choice Model Based on Cumulative Prospect Theory. Tversky and Kahneman [32] proposed cumulative prospect theory based on hierarchy-dependent utility theory. Cumulative prospect theory focuses on personal, psychological, and behavioral characteristics and replaces the decision weight in the prospect theory with a cumulative decision weight to better solve the problem of random dominance and the processing of multiple results.

Cumulative prospect theory divides the decision maker's risk selection process into two stages: editing and evaluation. The editing stage can be divided into setting reference points, establishing value functions, determining personal subjective probabilities, and establishing decision weight functions. In the evaluation stage, cumulative prospect theory considers the sort dependence of the probability of various possible outcomes of the alternatives and calculates and compares the prospects of the alternatives.

The prospect value is an index on which decision makers rely, as shown in the following formula:

$$
V=v(x) \pi(p) .
$$

In formula (6), $v(x)$ is the value function, and $\pi(p)$ is the decision weight function.

(1) Value function:

The specific expression of the value function $v(x)$ is as follows:

$$
v(x)= \begin{cases}a\left(x_{0}-x\right)^{\alpha}, & x_{0} \geq x, a>0, \alpha>0 \\ -b\left(x-x_{0}\right)^{\beta}, & x_{0}<x, b>0, \beta>0\end{cases}
$$

In formula (7), $x$ is the random event result, $x_{0}$ is the reference point, $a$ is the profit pursuit coefficient, $b$ is the loss avoidance coefficient, and $0<a<b$.

$\alpha$ and $\beta$ reflect the risk appetite level of the decision maker. The larger the values of $\alpha$ and $\beta$ are, the more likely the decision maker is to take risks, and $0<\alpha, \beta<1$.

(2) Decision weight function:

According to cumulative prospect theory, a prospect event result set $\left(x_{1}, x_{2}, \ldots, x_{n}\right)$ corresponds to a probability set $\left(p_{1}, p_{2}, \ldots, p_{n}\right)$, the probability of the result $x_{i}$ is $p_{i}$, the result set is arranged in the descending order as $\left(x_{1} \geq x_{2} \geq \cdots \geq x_{n}\right), \quad w^{+}$ represents the probability weight of the return, and $w^{-}$represents the probability weight of loss.

The expression of the probability weight function is

$$
\begin{aligned}
& w^{+}\left(p_{j}\right)=\frac{p_{j}^{\gamma}}{\left[p_{j}^{\gamma}+\left(1-p_{j}\right)^{\gamma}\right]^{1 / \gamma}}, \\
& w^{-}\left(p_{j}\right)=\frac{p_{j}^{\delta}}{\left[p_{j}^{\delta}+\left(1-p_{j}\right)^{\delta}\right]^{1 / \delta}} .
\end{aligned}
$$

The cumulative decision weight function $\pi(p)$ is generated by the probability weight function, and the expression is as follows:

$$
\begin{aligned}
& \pi_{i}^{+}=w^{+}\left(p_{i}+\cdots+p_{n}\right)-w^{+}\left(p_{i+1}+\cdots+p_{n}\right), \quad 0 \leq i \leq n, \\
& \pi_{j}^{-}=w^{-}\left(p_{-m}+\cdots+p_{j}\right)-w^{-}\left(p_{-m}+\cdots+p_{j-1}\right), \quad-m \leq j \leq 0 .
\end{aligned}
$$

The prospect value of the alternative can be expressed as

$$
V=\sum_{i-1}^{n} \pi^{+}\left(p_{i}\right) v\left(x_{i}\right)+\sum_{j-1}^{-m} \pi^{-}\left(p_{j}\right) v\left(x_{j}\right) .
$$

(3) Reference point setting:

As a single individual passenger is affected by many factors, such as personal experience and environment, different passengers have different feelings about the same event. According to research, when the reference point is set to the average value of the generalized cost of each route, it is more in line with the passengers' travel psychology. Therefore, this paper proposes using the average value of the generalized cost as the reference point. The calculation formula of the reference point is as follows:

$$
T_{\text {refer }}=\frac{1}{k} \sum_{i=1}^{k} C_{i}^{O D}
$$

3.2. Construction of the Multipath Probability Allocation Model Based on User Equilibrium. In this paper, based on the prospect value of each scheme calculated by the aforementioned cumulative prospect theory, the allocated passenger flow of each route is calculated according to the following calculation formula:

$$
f_{k}^{O D}=q^{O D} * \frac{\exp \left(-\theta * V_{k}^{O D}\right)}{\sum_{l \in k \text { path }} \exp \left(-\theta * V_{l}^{O D}\right)} .
$$

In formula (12), $\theta$ is the randomness of the description model; $q^{O D}$ is the passenger flow between $O D$ pairs; $f_{k}^{O D}$ is the distribution flow of the $k$-path between $O D$ pairs; and $V_{k}^{O D}$ is the cumulative prospect value of the $k$-path between $O D$ pairs. 
This paper uses the MSA algorithm, and the algorithm steps are as follows:

Step 1: initialization.

Step 2: calculation of impedance based on the generalized travel cost of passengers, use of the logic distribution method to distribute the passenger flow, and calculation of the route passenger flow and section passenger flow.

Step 3: iterative calculation.

Step 4: judge whether the convergence is based on the convergence function, convergence value, and number of convergence steps. Step 2 is repeated if the requirements are not met.

3.3. Overall Process of Simulating the Passenger Flow Deduction. The overall process of predicting the passenger flow within an urban rail transit network in real time is shown in Figure 1. The specific steps are as follows:

Step 1: predict the initial stage

The data are prepared and connected to the database before being read into all the infrastructure tables and parameter tables in the simulation process.

Step 2: prediction phase

The current state of passenger flow is determined (normal passenger flow prediction or emergency passenger flow prediction). The prediction stage includes the inbound volume prediction, passenger flow $O D$ prediction, and the passenger flow multipath distribution prediction. This paper employs real-time AFC statistical data and emergency line and length estimates by connecting to the database.

Inbound traffic forecast: at the beginning of each forecast time, based on the historical passenger flow inbound data table, the inbound traffic at each station is forecast within each forecasting period.

Passenger flow $O D$ prediction: according to the historical passenger flow $O D$ matrix, the inbound passenger flow is allocated according to the destination, and the passenger flow of each station's inbound passenger flow to the remaining stations, that is, the predicted passenger flow $O D$, is predicted in each forecast period.

Passenger flow multipath distribution prediction: the proportion of passenger flow that may be allocated for each route according to the cumulative prospect theory model is calculated, and the proportion of $O D$ traffic to each route is allocated.

Step 3: simulation phase

A simulation multiagent model is constructed according to the interaction among the overall road network scene, station, and passengers and other agents with their respective behavior rules, and accurate simulations are conducted considering the time, dynamic deduction, and loading of passenger flow data according to the time, statistics, and output according to the demand simulation calculation results within a certain time range.

Step 4: index calculation and storage of the result stage After the simulation calculation is completed, the calculation result data are quickly written into the database, and a report is generated.

Step 5: forecast end data update phase

In the data update stage, the corrected AFC data and $O D$ input data are updated in the same period.

3.4. Passenger Flow Impact Index System and Calculation of Emergencies. After the dynamic passenger flow allocation and simulation, it is necessary to identify the impact of the emergency passenger flow and perform an early warning of passenger flow based on the magnitude of the impact. Based on the detection of passenger flow anomalies, this paper establishes an urban rail transit emergency passenger flow impact index calculation model and then conducts a dynamic evaluation of the impacts of different types and levels of emergency events on passenger flow.

The index includes three aspects: degree of influence, scope of influence, and duration of influence. From the perspective of the severity of passenger congestion, the index is divided into different levels of congestion, namely, comfortable, general, and congested; from the perspective of the scope of influence, the index is divided into three levels, namely, station, line, and network; and from a time point of view, the index is divided into real time, short term, long term, and other levels. The influencing factors of the passenger flow impact index of emergencies are shown in Figure 2.

There are four passenger flow data sources for the emergency passenger flow impact index: inbound passenger flow, outbound passenger flow, interval passenger flow, and interchange passenger flow. The index calculation method proposed in this paper is based on the original passenger flow data. Compared with step-by-step recursive calculation methods such as the "station-line-network" approach, using the original flow data avoids an accumulation of errors due to step-by-step merging and is therefore more accurate. The passenger flow impact index system and calculation process of urban rail transit emergencies are shown in Figure 3.

\section{Case Analysis of Emergencies Based on the Beijing Rail Transit Network}

4.1. Data and Preliminary Processing. Urban rail transit AFC data include the inbound number, outbound number, line number, inbound time, and outbound time. This paper extracts and analyzes AFC data to extract the inbound and outbound passenger flow, sectional flow, and other data.

This paper selects the three-day normal daily passenger flow data before and after the emergency day (excluding special times, such as national statutory holidays and largescale events), and the track passenger flow time period is 15 minutes. To ensure the accuracy of the identification of 




FIGURE 1: Overall process of the real-time prediction of passenger flow in an urban rail transit network.



FIGURE 2: Factors affecting the passenger flow impact index under emergencies.

emergencies, based on previous experience and research, within a given period of time (excluding special times, such as national statutory holidays and large-scale events), the passenger flow data for a certain period on the same working day follow a normal distribution. This paper cleans the passenger flow data according to the $3 \sigma$ principle and removes the abnormal passenger flow data from the normally distributed historical passenger flow data. 


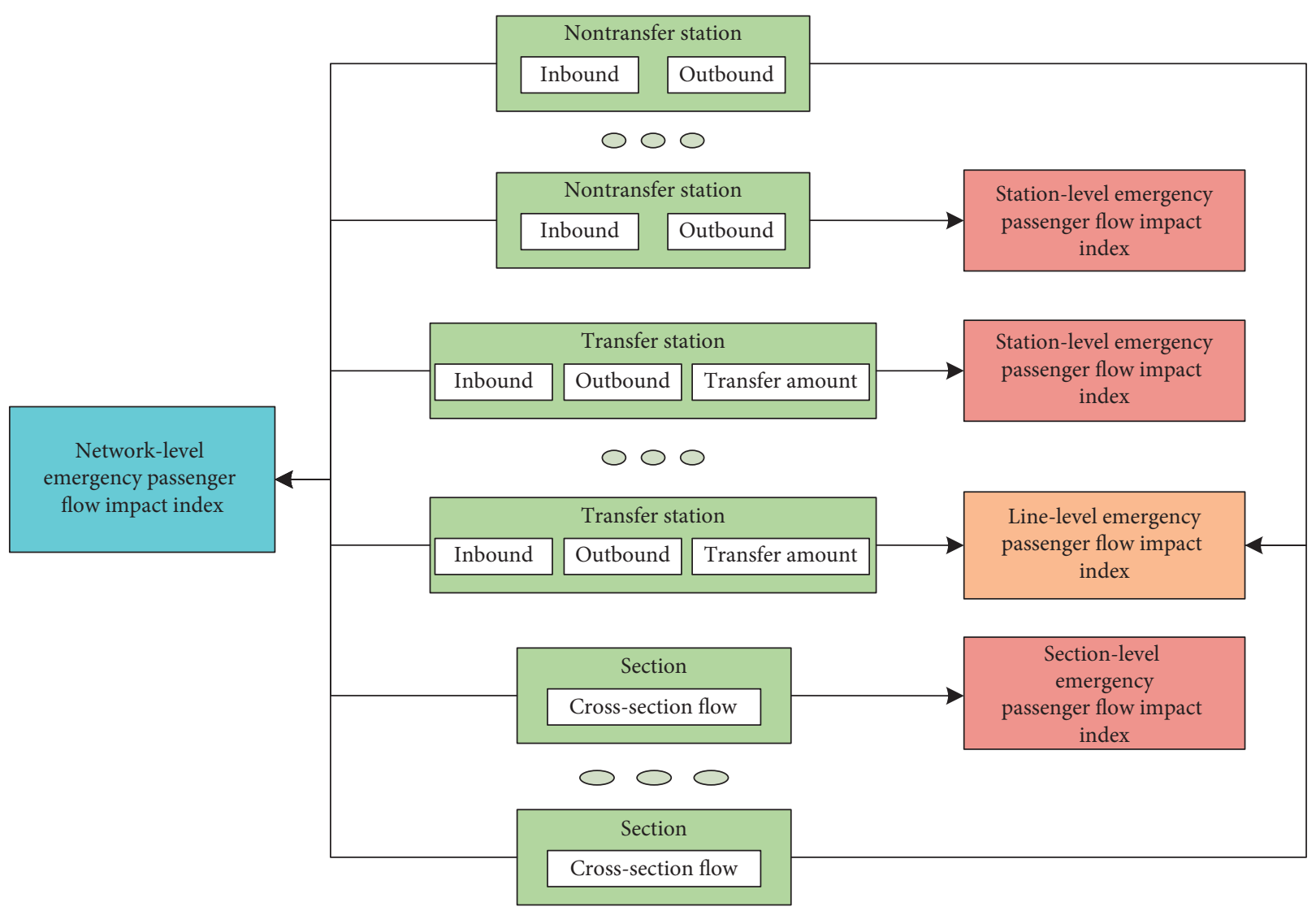

Figure 3: Passenger flow impact index system and calculation process of urban rail transit emergencies.

4.2. Analysis of Passenger Travel Behavior under Emergencies Based on a Multiple Logistic Regression Model. During an emergency, the travel choice behavior of passengers in the rail transit system will change. Based on questionnaire survey data and AFC passenger flow data, the study of passengers' travel choice behaviors provides basic support for $O D$ passenger flow analysis and travel delay time estimation. This paper considers only the situation when passengers are already inside the rail transit system when an emergency occurs.

4.2.1. Multinomial Logistic Travel Choice Behavior Regression Modeling Principle. The choice behavior of passengers after an emergency is selected as the dependent variable, and the conditional probability of choosing the $i$-th choice behavior is $P_{i}, i \in(1,2, \ldots, j-1, j+1, \ldots, m)$. The choice of the first passenger choice behavior is selected as the reference level, and the corresponding choice probability is $P_{j}$, $j \in(1,2, \ldots, m)$. Then, the multiclass logistic regression model is as follows:

$$
\ln \left(\frac{P_{i}}{P_{j}}\right)=\ln \left[\frac{P(y=i) \mid x}{P(y=j) \mid x}\right]=\alpha_{i}+\sum_{w=1}^{n} \beta_{i w} x_{w} .
$$

In formula (13), $x_{w}$ is the independent variable; $n$ is the number of independent variables; $m$ is the number of dependent variables; $\alpha_{i}, \beta_{i w}$ are the independent variable regression coefficient vectors; and $\ln \left(P_{i} / P_{j}\right)$ is the occurrence ratio of choice to choice.

4.2.2. Design of the Dependent and Independent Variables. According to the analysis, for the urban rail transit system, the travel choice behavior of passengers after an emergency occurs is divided into the following: leaving the station and changing to a bus, taxi, etc., to reach the destination; leaving the station and taking the rail transit from other rail stations but not leaving the station; changing the travel route and waiting for the incident to resume; and continuing to take the four types of rail transit travel. These behaviors are coded as shown in Table 3 . This paper selects 15 candidate independent variables and encodes the categorical variables as shown in Table 4.

4.2.3. Selection Behavior Analysis. According to the passenger choice behavior survey questionnaire, a logistic regression model was used to analyze the travel behavior of urban rail transit passengers, and the following conclusions were obtained:

(1) The social and economic attributes of passengers have certain impacts on passengers' behavior choices when facing emergencies, but these impacts are relatively small and can be ignored. 
TABLE 3: Description of dependent variables.

\begin{tabular}{lc}
\hline Chosen behavior & Code \\
\hline Exit the station and change to a bus, taxi, etc., to reach the destination & 1 \\
Exit the station and take the rail transit from other rail stations & 2 \\
Do not leave the station and change the travel route & 3 \\
Wait for the emergency to end and continue to take the rail transit & 4
\end{tabular}

TABle 4: Description of independent variables.

\begin{tabular}{|c|c|c|}
\hline Continuous variable & \multicolumn{2}{|r|}{ Travel distance } \\
\hline \multirow{12}{*}{ Categorical variables } & \multirow{4}{*}{ Passenger socioeconomic attributes } & Gender \\
\hline & & Age \\
\hline & & Job \\
\hline & & Monthly income \\
\hline & \multirow{2}{*}{ Passenger travel attributes } & Travel purpose \\
\hline & & Network familiarity \\
\hline & \multirow[b]{2}{*}{ Passenger's perception of emergencies } & Have you encountered an emergency? \\
\hline & & The longest tolerable event \\
\hline & \multirow{3}{*}{ Emergency attributes } & $\begin{array}{c}\text { The remaining travel time of passengers after the emergency } \\
\text { Time of the occurrence }\end{array}$ \\
\hline & & Location of the occurrence \\
\hline & & Influential impact \\
\hline & Information interference factors & Influencing station information \\
\hline
\end{tabular}

(2) When an emergency occurs, passengers who are familiar with the urban rail transit network tend to choose to detour inside the rail transit system. In contrast, passengers who occasionally take urban rail transit travel tend to stay and wait for the emergency to end because the urban rail transit network is relatively unfamiliar; these passengers are more flustered during emergencies, and there is a phenomenon of herding.

(3) The occurrence time, location, and impact of emergencies have important impacts on the choice of passengers. When predicting and guiding the passenger flow of emergencies, priority should be given to the selection of passengers under different occurrence times, locations, and impacts.

(4) In the case of giving passengers a certain amount of information to consider, most passengers will choose to change their initial choice behavior, and external information interference has an important influence on the choice of passengers.

4.3. Case Analysis of Emergencies Based on the Beijing Rail Transit Network. This article takes the Beijing urban rail transit network as an example with Tiantandongmen Station as the starting point and Zhangzizhonglu Station as the end point to analyze the route. The route contains three possible pathways, as shown in Figure 4.

When no emergencies occur, the attributes of the three alternative paths are shown in Table 5. It can be seen that the travel times of paths 2 and 3 are longer than the travel time of path 1 by 12 minutes, and both have three transfers, which are time-consuming. The probability of choosing path 1 is $100 \%$.

This article assumes that an emergency occurs in the section from Chongwenmen Station to Dongdan Station, and the time to resume traffic cannot be determined. At this time, path 1 is not accessible, paths 2 and 3 are affected by emergencies, and the path travel events are delayed to a certain extent. The delay time of each path caused by the emergencies is set to follow the distribution shown in Table 6.

According to the calculation of cumulative prospect theory, the selection probability of path 2 is $54.63 \%$, and the selection probability of path 3 is $45.37 \%$, which are closer to the results of the questionnaire survey. According to this analysis, passengers are more sensitive to losses, and the occurrence of emergencies makes path 2 lose fewer passengers than path 3 , which leads to different choices of travel routes for passengers. 


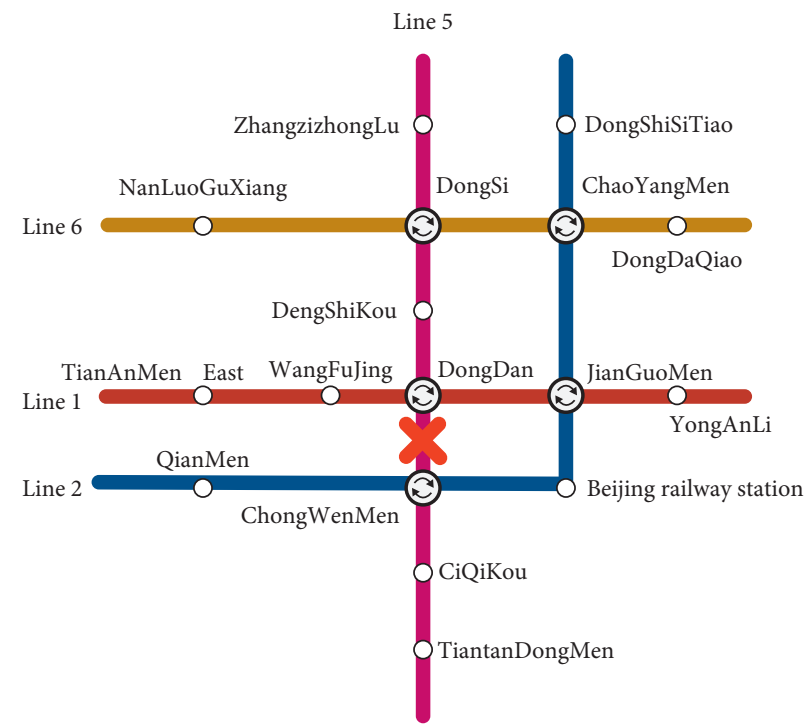

FIgURE 4: Travel route diagram.

TABLE 5: Path attribute table when no emergencies occur.

\begin{tabular}{|c|c|c|c|c|c|}
\hline ID & Path & Travel time (s) & Number of transfers & Transfer time (s) & Selection ratio \\
\hline 1 & $\begin{array}{c}\text { Tiantandongmen-Ciqikou-Chongwenmen-Dongdan- } \\
\text { Dengshikou-Dongsi-Zhangzizhonglu }\end{array}$ & 730 & 0 & 0 & $100 \%$ \\
\hline 2 & $\begin{array}{c}\text { Tiantandongmen-Ciqikou-Chongwenmen-Beijing railway } \\
\text { station-Jianguomen-Chaoyangmen-Dongsi- } \\
\text { Zhangzizhonglu }\end{array}$ & 860 & 3 & 1030 & 0 \\
\hline 3 & $\begin{array}{c}\text { Tiantandongmen-Ciqikou-Chongwenmen-Beijing railway } \\
\text { station-Jianguomen-Dongdan-Dengshikou-Dongsi- } \\
\text { Zhangzizhonglu }\end{array}$ & 924 & 3 & 840 & 0 \\
\hline
\end{tabular}

TABle 6: Probability distribution of delay time.

\begin{tabular}{|c|c|c|}
\hline Path & Delay time (s) & Probability of delay (\%) \\
\hline & 300 & 80 \\
\hline 2 & 600 & 20 \\
\hline 3 & $\begin{array}{l}600 \\
900\end{array}$ & $\begin{array}{l}80 \\
20\end{array}$ \\
\hline
\end{tabular}

\section{Conclusions}

To study the travel choice behavior of rail transit passengers under emergencies in depth, this paper proposes a prediction and early-warning model for the temporal and spatial distributions of rail transit passenger flow based on a cumulative prospect theory model, which makes up for the deficiencies of previous studies. Compared with the existing prediction methods, this method better simulates the travel decision-making process of rail transit passengers under emergencies, is closer to reality, and provides strong support for the accurate prediction of passenger flow between rail transit stations under emergencies. The model provides a theoretical basis for the government and related departments to formulate traffic management measures.
Specifically, this paper introduces cumulative prospect theory to study the route choice of urban rail transit passengers and performs the following work:

(1) The passenger's route choice preferences are analyzed under different influencing factors, and a generalized passenger travel cost model is established.

(2) The principle of establishing the reference point in the cumulative prospect theory model is analyzed, and a prediction and early-warning model for the temporal and spatial distributions of passenger flow during rail transit emergencies is constructed based on the cumulative prospect theory.

(3) According to the proposed prediction and earlywarning model for the temporal and spatial 
distributions of passenger flow during rail transit emergencies based on the cumulative prospect theory, a logistic regression model is used to analyze the travel behavior of urban rail transit passengers, and the Beijing urban rail transit network is taken as an example. The results show that the cumulative prospect theory can more accurately describe the decision-making behavior of passengers in route selection and can better reflect the needs of passengers traveling by rail transit under emergencies.

How to further update the data in the model to obtain more accurate results, study the changes in passenger behavior from day to day after short-term incidents, and develop a passenger flow organization method of subway stations when short-term incidents occur are all directions of future research.

\section{Data Availability}

The data used to support the findings of this study are available from the corresponding author upon request.

\section{Conflicts of Interest}

The authors declare that there are no conflicts of interest in this paper.

\section{Acknowledgments}

This work was jointly supported by the National Natural Science Foundation of China (no. U1834211), Postdoctoral Innovative Talent Project (no. BX20190029), and the State Key Laboratory of Rail Traffic Control and Safety (Contract no. RCS2020ZZ002).

\section{References}

[1] M. Zhou, H. Dong, B. Ning, and F. Wang, "Parallel urban rail transit stations for passenger emergency management," IEEE Intelligent Systems, 2019, In press.

[2] S. Liu, E. Yao, B. Li, and Y. Tang, "Forecasting passenger flow distribution between urban rail transit stations based on behavior analysis under emergent events," Journal of the China Railway Society, vol. 40, no. 9, pp. 22-29, 2018.

[3] X. Zhang, X. Li, J. Mehaffey, and G. Hadjisophocleous, “A probability-based Monte Carlo life-risk analysis model for fire emergencies," Fire Safety Journal, vol. 89, pp. 51-62, 2017.

[4] N. Zarboutis and N. Marmaras, "Searching efficient plans for emergency rescue through simulation: the case of a metro fire," Cognition, Technology \& Work, vol. 6, no. 2, pp. 117-126, 2004.

[5] S. Seer, D. Bauer, N. Brandle, and M. Ray, "Estimating pedestrian movement characteristics for crowd control at public transport facilities," in Proceedings of the 2008 11th International IEEE Conference on Intelligent Transportation Systems, pp. 742-747, Beijing, China, October 2008.

[6] H. Wang, L. Hong, and R. Xu, "Analysis of the emergency evacuation guide at metro station," Urban Mass Transit, vol. 15, no. 1, pp. 70-74, 2012.
[7] W. Zhu, "Mass passenger flows at rail transit stations: formation, impacts, and countermeasures," Urban Transport of China, vol. 11, no. 3, pp. 55-61, 2013.

[8] X. Li, "Research on forecast passenger flow bursted in urban rail station on data mining," Ph.D. thesis, Beijing Jiaotong University, Beijing, China, 2017.

[9] Y. Zhang and Z. Li, "Subway passenger transport organization under the condition of large passenger flow," Journal of Transportation Engineering and Information, vol. 15, no. 2, pp. 58-63, 2017.

[10] L. Zhang and F. Chen, "On large passenger flow operating organizations at metro station," Urban Mass Transit, vol. 14, no. 5, pp. 87-90, 2011.

[11] M. Zhou, H. Dong, Y. Zhao, P. A. Ioannou, and F.-Y. Wang, "Optimization of crowd evacuation with leaders in urban rail transit stations," IEEE Transactions on Intelligent Transportation Systems, vol. 20, no. 12, pp. 4476-4487, 2019.

[12] M. Zhou, H. Dong, P. A. Ioannou, Y. Zhao, and F.-Y. Wang, "Guided crowd evacuation: approaches and challenges," IEEE/CAA Journal of Automatica Sinica, vol. 6, no. 5, pp. 1081-1094, 2019.

[13] F. Li, R. Xu, and W. Zhu, "Generation of emergency scheme for urban rail transit by case-based reasoning," in Proceedings of the 12th International Conference on Computer System Design and Operation in Railways and Other Transit Systems, pp. 529-536, Beijing, China, August 2010.

[14] J. Preston, G. Wall, R. Batley, J. N. Ibáñez, and J. Shires, "Impact of delays on passenger train services," Transportation Research Record: Journal of the Transportation Research Board, vol. 2117, no. 1, pp. 14-23, 2009.

[15] A. Barron, P. C. Melo, J. M. Cohen, and R. J. Anderson, "Passenger-focused management approach to measurement of train delay impacts," Transportation Research Record, vol. 2351, no. 1, pp. 46-53, 2018.

[16] A. M. Pnevmatikou, M. G. Karlaftis, and K. Kepaptsoglou, "Metro service disruptions: how do people choose to travel?," Transportation, vol. 42, no. 6, pp. 933-949, 2015.

[17] R. Tsuchiya, Y. Sugiyama, K. Yamauchi, K. Fujinami, and T. Nakagawa, "Route-choice support system for passengers in the face of unexpected disturbance of train operations," in Proceedings of the Computers in Railways $X$ the Tenth International Conference, Prague, Czech Republic, July 2006.

[18] H. Sun, J. Wu, L. Wu, X. Yan, and Z. Gao, "Estimating the influence of common disruptions on urban rail transit networks," Transportation Research Part A: Policy and Practice, vol. 94, pp. 62-75, 2016.

[19] L. Hong, J. Gao, and R. Xu, "Calculation method of emergency passenger flow in urban rail network," Journal of Tongji University, vol. 39, no. 10, pp. 1485-1489, 2011.

[20] J. Li and P. Liang, "Quantitative analysis of affected passenger scale for rail transit operation cessation," Urban Mass Transit, vol. 16, no. 8, pp. 59-63, 2013.

[21] T. Huang, H. Zhu, and J. Yang, "The route choice model of urban rail traveler based on prospect theory," Urban Rapid Rail Transit, vol. 32, no. 2, pp. 67-71, 2019.

[22] X. Wang and J. Wu, "Cumulative prospect theory based urban railway traffic route choice for travelers in emergent events," Shandong Science, vol. 28, no. 2, 2015.

[23] Z. Wang, "Research on auxiliary technology of urban rail transit emergency decision," Ph.D. thesis, Tongji University, Shanghai, China, 2008.

[24] Q. Luo, "Research on theory and simulation of urban rail transit passenger flow distribution based on network operation," Ph.D. thesis, Tongji University, Shanghai, China, 2009. 
[25] K. Qiao, "Research on urban rail transit network operation characteristics and train regulation," Ph.D. thesis, Beijing Jiaotong University, Beijing, China, 2015.

[26] L. Wu, "Study on passenger travel route matching and impact of emergence in urban rail transit network based on AFC data," Ph.D. thesis, Beijing Jiaotong University, Beijing, China, 2016.

[27] $\mathrm{H}$. Yu, "A dynamic stochastic disequilibrium passenger flow assignment method and its application on a local disruption ofurban railway network," Ph.D. thesis, Beijing Jiaotong University, Beijing, China, 2015.

[28] F. Liu, "Influence of operation disruption on urban rail transit network and emergency strategy," Ph.D. thesis, Beijing Jiaotong University, Beijing, China, 2015.

[29] R. Xu, J. Ye, and H. Pan, "Method for early warning of heavy passenger flow at transfer station of urban rail transit network under train delay," China Railway Science, vol. 35, no. 5, pp. 127-133, 2014.

[30] W. Wang, C. Zhang, C. Zhu, and G. Fang, "Route selection method for emergency logistics based on cumulative prospect theory," China Safety Science Journal, vol. 3, 2017.

[31] H. Wang, H. Chen, W. Feng, and W. Liu, "Multi-dimensional travel decision model of heterogeneous commuters based on cumulative prospect theory," Journal of Zhejiang University, vol. 2, 2017.

[32] A. Tversky and D. Kahneman, "Advances in prospect theory: cumulative representation of uncertainty," Journal of Risk \& Uncertainty, vol. 5, pp. 297-323, 1992. 